BARROS JÚNIOR, A.P.; GRANGEIRO, L.C.; BEZERRA NETO, F.; NEGREIROS, M.Z.; SOUZA, J.O.; AZEVEDO, P.E.; MEDEIROS, D. C. Cultivo da alface em túneis baixos de agrotêxtil. Horticultura Brasileira, Brasília, v.22, n.4, p. 801-803, out-dez 2004.

\title{
Cultivo da alface em túneis baixos de agrotêxtil
}

\author{
Aurélio P. Barros Júnior; Leilson C. Grangeiro; Francisco Bezerra Neto; Maria Zuleide de Negreiros; \\ Jean de O. Souza ${ }^{1 ;}$ Pascalle E. de Azevedo; Damiana Cleuma Medeiros
}

ESAM, Depto. Ciências Vegetais, C. Postal 137, 59625-900 Mossoró-RN; E-mail: leilson@esam.br

\begin{abstract}
RESUMO
O experimento foi conduzido na horta da ESAM, de março a abril de 2004, com o objetivo de avaliar o desempenho de cultivares da alface em túneis baixos de agrotêxtil. O delineamento experimental utilizado foi de blocos casualizados completos em esquema fatorial 2 x 3, com quatro repetições. Os tratamentos foram constituídos pela combinação de duas cultivares de alface (Tainá e Babá de Verão) e três tipos de cobertura (dois túneis baixos de $50 \mathrm{~cm}$ de altura de agrotêxtil branco com gramatura de $13 \mathrm{~g} / \mathrm{m}^{2}$ e $40 \mathrm{~g} / \mathrm{m}^{2}$ e sem cobertura). Avaliou-se a altura e diâmetro de plantas, número de folhas por planta, massa seca da parte aérea e produtividade. A cultivar Babá de Verão apresentou melhor desempenho em altura de plantas, número de folhas e produtividade. O túnel baixo de agrotêxtil branco com gramatura de $40 \mathrm{~g} / \mathrm{m}^{2}$ promoveu maior altura, diâmetro e produtividade de alface.
\end{abstract}

Palavras-chave: Lactuca sativa L., cultivo protegido, rendimento.

\begin{abstract}
\section{Lettuce cultivation in low tunnels of agricultural textile}

The yield of lettuce cultivated under low tunnels of agricultural textile was evaluated in Mossoró, Rio Grande do Norte State, Brazil. The experiment was carried out from March to April of 2004, in a randomized complete blocks design with three treatments and four replications. The treatments were: low tunnel (with $50 \mathrm{~cm}$ of height) of white agricultural textile with basic weight of $40 \mathrm{~g} / \mathrm{m}^{2}$; low tunnel (with $50 \mathrm{~cm}$ of height) of white agricultural textile with basic weight of $13 \mathrm{~g} / \mathrm{m}^{2}$ and control (treatment with no coverage). Evaluations of plant height and diameter, number of leaves per plant, shoot dry matter and yield were done. Cultivar Babá de Verão presented greater plant height, number of leaves per plant and yield. The low tunnel of agricultural textile with basic weight of $40 \mathrm{~g} / \mathrm{m}^{2}$ presented superior results of plant height, diameter and yield.
\end{abstract}

Keywords: Lactuca sativa L., soil coverage, yield.

(Recebido para publicação em 10 de agosto de 2004 e aceito em 13 de setembro de 2004)

$\mathrm{O}$ agrotêxtil é confeccionado a parir de longos filamentos de polipropileno que são colocados em camadas e soldados entre si por temperaturas apropriadas, constituindo-se um material muito leve e de resistência suficiente para sua utilização na agricultura. Algumas das vantagens da utilização do agrotêxtil em cultivo protegido é a possibilidade de sua colocação e retirada em qualquer fase de desenvolvimento da cultura e a possibilidade de ser colocado diretamente sobre as plantas ou solo sem a necessidade de estruturas de sustentação.

Na região Sul do Brasil, além das estufas plásticas não climatizadas, está sendo utilizado o agrotêxtil que, em alguns países da Europa já é usado na agricultura para proteção de plantas, desde o início dos anos 80. No Brasil, os trabalhos de pesquisa com agrotêxtil iniciaram-se no final da década de 90, na região dos Campos Gerais, no estado do Paraná, onde hoje é utilizado por produtores de hortaliças para proteção de cultivos.

Para culturas como alface (Fuello et al., 1993; Otto et al., 2001), mandioquinha salsa (Reghin et al.,
2000), morango (Otto et al., 2000), pimentão (Pereira et al., 2001), couvechinesa (Colturato et al., 2001) e feijãovagem (Pereira et al., 2003) a utilização do agrotêxtil como proteção de plantas tem apresentado bons resultados, mostrando como vantagens de sua utilização, barreira física contra geadas, manutenção da umidade do solo, precocidade e qualidade na produção de mudas, melhoria e sanidade do produto final, precocidade e aumento da produção. Além disso, apresenta facilidade de manuseio e menor investimento inicial, se comparado com outros sistemas de cultivo protegido. Como em qualquer sistema utilizado no cultivo protegido, o uso do agrotêxtil também modifica o ambiente sob proteção.

$\mathrm{O}$ agrotêxtil pode ser colocado diretamente sobre a cultura após o transplantio, sobre o solo semeado diretamente ou com a utilização de uma estrutura de apoio (túneis). Na região de Ponta Grossa, verificou-se maior precocidade e incrementos de até $124 \%$ na massa seca de raízes de beterraba cultivada sob condições de agrotêxtil (Otto e Reghin, 1999). Em cultivo de pimen- tão, a colocação do agrotêxtil sobre as mudas recém transplantadas danificou o ponto de crescimento das plantas, atrasando o início da fase reprodutiva, porém, resultou em aumento da produção total (Foltran et al.,1999). Borosic et al. (1994), citaram que a utilização do agrotêxtil como forma de proteção da planta na cultura da alface, proporcionou ganhos significativos na produtividade em até $82 \%$ quando comparada ao cultivo sem proteção.

No Estado do Rio Grande do Norte, a produção da alface é baixa quando comparada com outras regiões do país, não atendendo com isso a sua demanda interna. Os métodos de produção existentes são rudimentares e na maioria das vezes não correspondem às expectativas de produções esperadas. Dentre os fatores que estão associados a estes baixos rendimentos, destaca-se o baixo nível de tecnologia, principalmente, aqueles associados à proteção da cultura contra as elevadas temperaturas e luminosidade na região (Queiroga, 2000). Nessa região, embora o agrotêxtil seja bastante utilizado nas culturas do melão e da melancia, sobre as plantas 
Tabela 1. Altura (ALT) e diâmetro (DAM) de plantas, número de folhas/planta (NF), massa seca da parte aérea (MSPA) e produtividade (PR) de duas cultivares de alface. Mossoró, ESAM, 2004.

\begin{tabular}{lccccc}
\hline Cultivares & ALT (cm) & DAM $(\mathbf{c m})$ & NF & $\begin{array}{c}\text { MSPA } \\
\text { (g/planta) }\end{array}$ & PR (t/ha) \\
\hline Tainá & $17,5 \mathrm{~b}^{1}$ & $23,0 \mathrm{a}$ & $13,3 \mathrm{~b}$ & $6,9 \mathrm{a}$ & $24,0 \mathrm{~b}$ \\
Babá de Verão & $21,2 \mathrm{a}$ & $23,3 \mathrm{a}$ & $25,8 \mathrm{a}$ & $7,0 \mathrm{a}$ & $30,0 \mathrm{a}$ \\
\hline CV (\%) & 10,36 & 10,92 & 9,01 & 10,60 & 10,08 \\
\hline
\end{tabular}

${ }^{1}$ Médias seguidas pela mesma letra na coluna não diferem entre si pelo teste de Tukey ao nível de $5 \%$ de probabilidade.

Tabela 2. Altura (ALT) e diâmetro (DAM) de plantas, número de folhas/planta (NF), massa seca da parte aérea (MSPA) e produtividade (PR) de três tipos de cobertura. Mossoró, ESAM, 2004.

\begin{tabular}{lccccc}
\hline $\begin{array}{l}\text { Tipos de } \\
\text { cobertura }\end{array}$ & ALT $(\mathbf{c m})$ & DAM $(\mathbf{c m})$ & NF & $\begin{array}{c}\text { MSPA } \\
\text { (g/planta) }\end{array}$ & PR (t/ha) \\
\hline Sem cobertura & $18,2 \mathrm{~b}^{1}$ & $21,9 \mathrm{~b}$ & $19,8 \mathrm{a}$ & $6,6 \mathrm{a}$ & $24,0 \mathrm{~b}$ \\
Agrotêxtil $13 \mathrm{~g} / \mathrm{m}^{2}$ & $18,3 \mathrm{~b}$ & $21,7 \mathrm{~b}$ & $19,5 \mathrm{a}$ & $7,0 \mathrm{a}$ & $27,0 \mathrm{~b}$ \\
Agrotêxtil $40 \mathrm{~g} / \mathrm{m}^{2}$ & $21,6 \mathrm{a}$ & $25,8 \mathrm{a}$ & $19,5 \mathrm{a}$ & $7,1 \mathrm{a}$ & $31,0 \mathrm{a}$ \\
\hline $\mathrm{CV}(\%)$ & 10,36 & 10,92 & 9,01 & 10,60 & 10,08 \\
\hline
\end{tabular}

${ }^{1}$ Médias seguidas pela mesma letra na coluna não diferem entre si pelo teste de Tukey ao nível de $5 \%$ de probabilidade.

após o transplantio até início de floração, com o objetivo de reduzir o ataque de pragas, nenhum trabalho científico foi realizado com a finalidade de avaliar o efeito direto do agrotêxtil no rendimento e qualidade das hortaliças. O presente trabalho teve como objetivo avaliar o rendimento da alface cultivada em túneis baixos de agrotêxtil.

\section{MATERIAL E MÉTODOS}

O experimento foi realizado na horta da ESAM, de março a abril de 2004. O solo foi classificado como Argissolo Vermelho-Amarelo Eutrófico. Da área experimental foram retiradas amostras de solo, cuja análise química revelou: $\mathrm{pH}_{\text {(água) }}=7,9 ; \mathrm{P}=157 \mathrm{mg} \mathrm{dm}^{-3} ; \mathrm{K}=0,3$ $\mathrm{cmol}_{\mathrm{c}} \mathrm{dm}^{-3} ; \mathrm{Ca}=3,2 \mathrm{cmol}_{\mathrm{c}} \mathrm{dm}^{-3}$ e $\mathrm{Mg}=$ $1,0 \mathrm{cmol} \mathrm{dm}^{-3}$.

$\mathrm{O}$ delineamento experimental utilizado foi de blocos casualizados completos, em esquema fatorial $2 \times 3$ com quatro repetições. Os tratamentos do fatorial constituíram da combinação de duas cultivares de alface (Tainá e Babá de Verão) e três tipos de cobertura (túnel baixo de $50 \mathrm{~cm}$ de altura de agrotêxtil branco com gramatura de $13 \mathrm{~g} / \mathrm{m}^{2}$, túnel baixo de $50 \mathrm{~cm}$ de altura de agrotêxtil branco com gramatura de $40 \mathrm{~g} / \mathrm{m}^{2}$ e o tratamento sem cobertura). Cada parce- la foi constituída de cinco fileiras, sendo consideradas como úteis as três fileiras centrais, com uma área de 0,48 $\mathrm{m}^{2}$, contendo doze plantas, no espaçamento de 0,20x0,20 m.

A semeadura foi realizada em copos descartáveis de $150 \mathrm{ml}$, preenchidos com o substrato comercial GoldMix $47^{\circledR}$ em 05/03/2004, utilizando-se 3 a 5 sementes por recipiente. Após a germinação, realizou-se o desbaste deixando uma muda por recipiente. $O$ transplantio foi efetuado 20 dias após a semeadura, quando as mudas apresentavam de 4 a 5 folhas definitivas, no espaçamento de $0,20 \times 0,20 \mathrm{~m}$.

$\mathrm{O}$ agrotêxtil foi colocado após o transplantio sobre arcos de ferro, com altura de $50 \mathrm{~cm}$, sendo o mesmo fixado com fitilho. Em cada lateral do túnel de agrotêxtil foi deixado, uma abertura de aproximadamente $10 \mathrm{~cm}$. As plantas permaneceram protegidas com agrotêxtil durante o ciclo da cultura (27 dias após o transplantio), sendo retirado apenas para as realizações dos tratos culturais (capinas e adubações).

As adubações foram realizadas com base na análise do solo, sendo aplicado em fundação 80 t/ha de esterco bovino curtido, $40 \mathrm{~kg} / \mathrm{ha}$ de $\mathrm{N}$ na forma de uréia, $60 \mathrm{~kg} / \mathrm{ha}$ de $\mathrm{P}_{2} \mathrm{O}_{5}$ na forma de superfosfato simples e $30 \mathrm{~kg} / \mathrm{ha}$ de $\mathrm{K}_{2} \mathrm{O}$ na forma de cloreto de potássio. Foi efetuada uma adubação nitrogenada em cobertura, aos quinze dias após transplantio com $40 \mathrm{~kg} / \mathrm{ha}$ de $\mathrm{N}$ na forma de uréia.

A colheita ocorreu 47 dias após a semeadura, sendo as características avaliadas: altura e diâmetro das plantas (cm), número de folhas, massa seca da parte aérea (g/planta) e produtividade ( $\mathrm{t} /$ ha). As análises estatísticas foram realizadas através do software SPSS/PC (Norusis, 1990).

\section{RESULTADOS E DISCUSSÃO}

Não se observou efeito significativo da interação cultivares e proteção das plantas para nenhuma característica avaliada. A cultivar Babá de Verão foi superior para altura de plantas, número de folhas e produtividade, enquanto que para diâmetro e massa seca não houve diferença significativa entre as cultivares (Tabela 1).

A produtividade da cultivar Babá de Verão foi $25 \%$ superior a da Tainá, diferentemente do observado por Oliveira (2004), que não verificou diferença significativa, quando avaliou o desempenho de diversas cultivares da alface no município de Mossoró. Esta produtividade superou a média da região, que é de 11 t/ha. Segundo Ramos (1995) a baixa produtividade observada na região deve-se a utilização de cultivares pouco adaptadas às temperaturas e luminosidade elevadas, como também a não adoção de práticas que visem minimizar os efeitos extremos da temperatura e luminosidade local. Queiroga (2000), obteve produtividades superiores às encontradas neste trabalho com as cultivares Great Lakes (57,9 t/ha), Verônica (39,1 t/ha) e Regina (46,9 t/ha). Em regiões de baixa latitude, como é o caso de Mossoró, tem-se uma maior incidência direta da radiação solar. Espécies vegetais, que necessitam de temperaturas mais amenas, como a alface, para seu perfeito desenvolvimento sofrem duplamente com alta radiação, excesso de luminosidade e temperatura elevada que podem comprometer cerca de $25 \%$ da produtividade da alface (Rocha, 2000).

Com exceção do número de folhas e da massa seca da parte aérea, o túnel 
baixo de agrotêxtil branco com gramatura de $40 \mathrm{~g} / \mathrm{m}^{2}$ foi superior ao agrotêxtil de $13 \mathrm{~g} / \mathrm{m}^{2}$ e ao tratamento sem cobertura para as demais características, sendo que, entre os dois últimos tratamentos não houve diferença significativa (Tabela 2). Provavelmente, devido o agrotêxtil de $40 \mathrm{~g} / \mathrm{m}^{2}$ possuir uma espessura maior, proporcionou uma melhor proteção às plantas em relação ao tratamento com o agrotêxtil de $13 \mathrm{~g} / \mathrm{m}^{2}$ (espessura menor), contra os efeitos das elevadas temperaturas e luminosidade local, e também das precipitações que ocorreram durante o período de condução do experimento $(120 \mathrm{~mm})$.

$\mathrm{O}$ agrotêxtil de gramatura de $40 \mathrm{~g} /$ $\mathrm{m}^{2}$ proporcionou uma produtividade $14,8 \%$ superior ao de $13 \mathrm{~g} / \mathrm{m}^{2}$ e de $29,2 \%$ ao tratamento sem cobertura. Reghin et al. (2002a) em experimento na região de Ponta Grossa (PR), verificaram que a proteção das plantas de alface da cultivar Veneza Roxa, com agrotêxtil branco de $25 \mathrm{~g} / \mathrm{m}^{2}$, durante todo o ciclo de cultivo (38 dias após transplantio), favoreceu a maior massa fresca e produtividade. Quando a proteção das plantas foi combinada com a cobertura do solo, os autores verificaram que, os tratamentos onde as plantas foram protegidas com agrotêxtil branco de gramatura de $20 \mathrm{~g} / \mathrm{m}^{2}$, independente da cobertura do solo, proporcionaram menor percentagem de folhas queimadas pela geada, precocidade na colheita de seis dias e peso médio da cabeça da alface $32,64 \%$ superior ao tratamento sem proteção (Reghin et al., 2002 b). Em mini-alface, cultivar AF-469, a proteção das plantas com agrotêxtil em relação às plantas que não foram protegidas apresentaram o ciclo reduzido em 10 dias e um produto de melhor qualidade (Reghin et al., 2002c).

Reghin et al. (2002d) também estudaram o desempenho de "pak choi" (repolho branco chinês) sob proteção de agrotêxtil branco de 17 e $25 \mathrm{~g} / \mathrm{m}^{2}$ e verificaram que, o agrotêxtil de maior espessura $\left(25 \mathrm{~g} / \mathrm{m}^{2}\right)$ proporcionou maior precocidade e peso da massa seca por planta. Segundo os autores, a utilização desse material favoreceu a formação de um microclima favorável ao desenvolvimento da planta, protegendo naquelas condições principalmente, das baixas temperaturas. Ling et al. (1998) tam- bém em pak choi, obtiveram melhores resultados com o agrotêxtil branco de $30 \mathrm{~g} / \mathrm{m}^{2}$ em relação ao de 20 e $40 \mathrm{~g} / \mathrm{m}^{2}$.

Segundo Rocha (2000), as plantas de alface quando submetidas ao sombreamento, podem sofrer alterações morfológicas. Plantas expostas diretamente a radiação solar formaram folhas alongadas e estreitas, ao contrário daquelas sombreadas, que produziram folhas com formato oval, ou seja, curta e larga do ápice para a base. Nas condições de Mossoró, Queiroga (2000), verificou que o sombreamento na fase de mudas, com tela de cor branca, favoreceu a maior produtividade e acúmulo de massa seca na cultura da alface. Segundo o autor, esses resultados devem-se provavelmente, a uma melhor condição de temperatura e luminosidade na fase de mudas e confirmam em parte os obtidos por Edmond et al. (1967), que ao afirmar que quando uma cultura está sendo conduzida dentro de uma variação ótima de luminosidade com outros fatores favoráveis, a fotossíntese é elevada e a quantidade de carboidratos utilizados para o crescimento e desenvolvimento da planta é alta.

A alface produzida nesta pesquisa apresentou excelente qualidade, para os padrões locais. Além de não se fazer uso de qualquer tipo de defensivo para combater a ação de pragas e doenças.

O agrotêxtil pode ser utilizado na proteção das plantas pelos produtores de alface da região, como uma alternativa para minimizar os efeitos das altas temperaturas e luminosidade, melhorando a produtividade e qualidade do produto.

\section{LITERATURA CITADA}

BOROSIC, J.; ZUTIC, I.; MEBLIN, D. Spring crops of lettuce, carrot and pak-choi growth under direct covers. Reports of 13 Internacional Congress of C.I.P.A., v.1, 1994, 22 p.

COLTURATO, A.B.; JACCOUD FILHO, D.S.; OTTO, R.F.; GASPERRINI, L. Avaliação da ocorrência de Alternaria brassicae em couve-chinesa cultivada sob agrotêxtil e ambiente natural na região de Ponta Grossa - Paraná. Horticultura Brasileira, Brasília, v.19, n.2, Suplemento CD-ROM, 2001.

EDMOND, J.B.; SENN, T.L.; ANDREWS, F.S Princípios de horticultura. México: Continental, 1967. p.119-134.

FOLTRAN, B.N.; OTTO, R.F.; REGHIN, M.Y. Uso da proteção de "não tecido" de polipropileno sobre a cultura do pimentão, em Ponta GrossaPR. Horticultura Brasileira, Brasília, v.17, n.3, p.286, Resumos, 1999.
FUELLO, M.A.; BARANDA, A.A.; ARRIETA, A.I. Semiforzado de lechuga com agrotestiles Producción de otoño - inverni al aire libre. Hortofruticultura, v.4, p.37-40, 1993.

LING, L.; HU, J.L.; LI, S.J. Influence of different shade covers on production of pak choi and spinach. China vegetables, n.4, p.19-21, 1998.

OLIVEIRA, E.Q. Desempenho agroeconômico do bicultivo de alface consorciada, em faixa, com cenoura. 2004. 76 f. (Tese mestrado), ESAM, Mossoró.

OTTO, R.F.; REGHIN, M.Y. Respostas produtivas da beterraba cultivada sob "não tecido" de polipropileno, durante o inverno de Ponta Grossa-PR. Horticultura Brasileira, Brasília, v.17, n.3, p.311, Resumos, 1999.

OTTO, R.F.; REGHIN, M.Y.; TIMOTIO, P.C.; PEREIRA, A.V.; MADUREIRA, A. Respostas produtivas de duas cultivares de morango cultivadas sob "não tecido" de polipropileno no município de Ponta Grossa-PR. Horticultura Brasileira, Brasília, v.18, n.3, Suplemento CD-ROM, 2000.

OTTO, R.F.; REGHIN, M.Y.; SÁ, G.D. Utilização do 'não tecido' de polipropileno como proteção da cultura de alface durante o inverno de Ponta Grossa-PR. Horticultura Brasileira, Brasília, v.19, n.1, p. 49-52, 2001.

PEREIRA, A.V.; OTTO, R.F.; REGHIN, M.Y. Efeito da proteção com agrotêxtil na produtividade da cultura do pimentão em Ponta Grossa-PR. Horticultura Brasileira, Brasília, v.19, n.2, Suplemento CD-ROM, 2001.

PEREIRA, A.V.; OTTO, R.F.; REGHIN, M.Y Resposta do feijão-vagem cultivado sob proteção com agrotêxtil em duas densidades de plantas. Horticultura Brasileira, Brasília, v.21, n.3, p.564569, 2003.

QUEIROGA, R.C.F. Produção de alface em função de cultivares e tipos de tela de sombreamento nas condições de Mossoró-RN. 2000. 28 f. (Tese mestrado), ESAM, Mossoró.

RAMOS, J.E.L. Sombreamento e tipos de recipientes na formação de mudas e produção de alface. 1995. 53 f. (Tese mestrado), ESAM, Mossoró.

REGHIN, M.Y.; OTTO, R.F.; SILVA, J.B.C. "Stimulate Mo" e proteção com "Tecido-não-Tecido" no pré enraizamento de mudas de mandioquinha-salsa. Horticultura Brasileira, Brasília, v.18, n.1, p.53 - 56, 2000.

REGHIN, M.Y.; DALLA PRIA, M.; OTTO, R.F.; FELTRIM, A.L.; VINNE, J. Cultivo da alface com proteção de agrotêxtil em diferentes períodos. Horticultura Brasileira, Brasília, v.20, n.2, Suplemento CD-ROM, 2002a.

REGHIN, M.Y.; PURÍSSIMO, C.; DALLAPRIA, M.; FELTRIM, A.L.; FOLTRAN, M.A. Técnicas de cobertura do solo e de proteção de plantas no cultivo da alface. Horticultura Brasileira, Brasília, v.20, n.2, Suplemento CD-ROM, 2002b.

REGHIN, M.Y.; DALLA PRIA, M.; OTTO, R.F.; FELTRIM, A.L.; VINNE, J. Sistemas de cultivo com diferentes espaçamentos entre plantas em alface mini. Horticultura Brasileira, Brasília, v.20, n.2, Suplemento CD-ROM, 2002c.

REGHIN, M.Y.; OTTO, R.F.; VINNE, J.; FELTRIM, A.L.. Produção de repolho branco chinês (pak choi) sob proteção com "não tecido" de polipropileno. Horticultura Brasileira, Brasília, v.20, n.2, p.233-236, 2002d.

ROCHA, R.C.C. Tipos e alturas de sombrites na produção de alface sob temperatura $e$ luminosidade elevadas. 2000. 73 f. (Tese mestrado), ESAM, Mossoró

NORUSIS, M.J. SPSS/PC Statistics. Illinois: SPSS Inc., $1990.320 \mathrm{p}$. 